\title{
Galectin-3 promotes the adhesion, but not the migration of thyroid carcinoma cells in a $\beta$-galactoside-specific manner
}

\author{
JOCHEN WINTER ${ }^{1}$, ALEXANDER GLASSMANN ${ }^{2,6}$, DOMINIK KRAUS $^{3}$, STILLA FREDE $^{4}$, \\ NADINE VEIT ${ }^{5}$ and RAINER PROBSTMEIER ${ }^{5}$ \\ ${ }^{1}$ Oral Cell Biology Group, Department of Periodontology, Operative and Preventive Dentistry, \\ University of Bonn, 53111 Bonn; ${ }^{2}$ Life Science Inkubator GmbH, 53175 Bonn; \\ ${ }^{3}$ Department of Prosthodontics, Preclinical Education and Material Sciences, University of Bonn, 53111 Bonn; \\ ${ }^{4}$ Department of Anesthesiology and Intensive Care Medicine, and ${ }^{5}$ Neuro- and Tumor Cell Biology Group, \\ Department of Nuclear Medicine, University Hospital Bonn, 53127 Bonn, Germany
}

Received July 6, 2020; Accepted January 13, 2021

DOI: $10.3892 /$ wasj.2021.85

\begin{abstract}
In thyroid carcinoma cells, the soluble $\beta$-galactosidespecific lectin, galectin-3, is extra- and intracellularly expressed and plays a significant role in thyroid cancer diagnosis. The functional relevance of this molecule, particularly in its extracellular environment however, warrants further elucidation. To gain insight into this topic, the present study characterized principal functional properties of galectin-3 in 3 commonly used thyroid carcinoma cell lines (B-CPAP, Cal-62 and FTC-133) that express the molecule intra- and extracellulary. Cell-intrinsic galectin-3 harbors a functional carbohydrate recognition domain as determined by affinity purification. Moreover, cell surface expressed galectin-3 can be partially removed by treatment with lactose or asialofetuin, but not with sucrose. Thyroid carcinoma cells adhere to substrate-bound galectin-3 in a $\beta$-galactoside-specific manner, whereby only cell adhesion, but not cell migration is promoted. Thus, thyroid tumor cells harbor functional active galectin-3 that, inter alia, specifically interacts with cell surface-expressed molecular ligands in a $\beta$-galactoside-dependent manner, whereby the molecule can at least interfere with cell adhesion. The modulation of galectin-3 expression level or its ligands in such tumor cells could be of therapeutic interest and needs further experimental clarification.
\end{abstract}

Correspondence to: Dr Jochen Winter, Oral Cell Biology Group, Department of Periodontology, Operative and Preventive Dentistry, University of Bonn, Welschnonnenstrasse 17, 53111 Bonn, Germany E-mail: jochen.winter@ukbonn.de

Present address: ' ${ }^{6}$ epartment of Immunology and Cell Biology, University of Applied Science Bonn-Rhein-Sieg, 53359 Rheinbach, Germany

Key words: adhesion, $\beta$-galactoside, galectin-3, migration, thyroid cancer

\section{Introduction}

The incidence of thyroid cancer, which represents the most common endocrine cancer, has increased over the past decades (1). Thus, there is an urgent need to further improve thyroid cancer diagnosis and therapy, as is particularly the case for advanced iodine-refractory thyroid cancer (2). A significant contribution of the animal lectin, galectin-3, in the context of thyroid tumors has been well-established $(3,4)$. The molecule belongs to the galectin family of soluble lectins that are specific for $\beta$-galactosides. It is the only chimera type within the galectin family and consists of 3 distinct domains: An $\mathrm{NH}_{2}$-terminal domain, a proline-rich collagen-like domain and a $\mathrm{COOH}$-terminal carbohydrate recognition domain (CRD). As other galectins, galectin-3 interacts with simple $\beta$-galactosides; however, its affinity towards natural and more complex polylactosamine structures is higher (5). Dependent on the cell type or cell line, the molecule is expressed intra(cytosol and nucleus) and extracellularly (plasma membrane and extracellular matrix) (6,7). It can interact with a variety of other molecules, whereby, particularly in the intracellular environment, also carbohydrate-independent interactions are possible. The extracellular expression of galectin-3 has been reported for numerous normal, as well as tumor cells, whereby it can fulfil different functions. Galectin-3 secreted by tumor cells binds both glycosylated IFN $\gamma$ and glycoproteins of the tumor extracellular matrix, thus avoiding IFN $\gamma$ diffusion and the formation of an IFN $\gamma$-induced chemokine gradient required for $\mathrm{T}$ cell infiltration (8). In T-cells, galectin-3 induces apoptosis, whereby both, the CRD as well as the $\mathrm{NH}_{2}$-terminal tail are involved (9). Extracellular galectin-3 programs multidrug resistance via $\mathrm{Na}^{+} / \mathrm{K}^{+}$-ATPase and P-glycoprotein-dependent signaling mechanisms (10). Galectin-3 exhibits also chemokinetic or chemotactic effects (11), whereby cell migration can be induced in an ERK1/2-MAPK-dependent manner (12). Additionally, galectin-3 interacts intracellularly with the Ras/ERK1/2 pathway, in that it augments K-Ras, but attenuates ERK activity $(13,14)$.

In comparison to normal thyroid or its benign alterations, galectin-3 is expressed almost without exception in 
differentiated thyroid carcinomas, as well as in fractions of poorly differentiated and anaplastic thyroid carcinomas (15). As galectin-3 expression is downregulated by wild-type (wt) p53, the high expression level of galectin-3 in differentiated thyroid carcinomas appeared to be paradoxical, until it could be demonstrated that in such types of tumors, the p53 activator homeodomain interacting protein kinase-2 (HIPK2) is lacking, a kinase which is necessary for an adequate function of p53. The loss of HIPK2 leads to galectin-3 overexpression and the inhibition of apoptosis (16).

Recently, the cell surface expression of galectin-3 has also been demonstrated for human thyroid tumor cell lines, prompting D'Alessandria et al (2016) to verify whether galectin-3 antibodies can be used in immunoPET studies (3). In murine xenograft models of human thyroid cancer, a radiolabeled Fab-fragment of a galectin-3 specific antibody allowed the specific imaging of the thyroid tumors $(3,4)$. The present study focused primarily on the functional significance of galectin-3 in the extracellular environment and characterized its relevance in the context of thyroid tumor cell adhesion and migration.

\section{Materials and methods}

Cell lines and culture conditions. The human de-differentiated thyroid carcinoma cell line, B-CPAP, and the human follicular thyroid cancer cell line, FTC-133, were provided by Professor G. Brabant (Department of Endocrinology, Christie Hospital, Manchester, UK) and were subjected to STR profiling and verification (Eurofins Genomics Germany $\mathrm{GmbH}$ ). The human anaplastic thyroid cancer cell line, Cal-62, was obtained from Leibniz Institute DSMZ - German Collection of Microorganisms and Cell Cultures. All cells were tested as negative for mycoplasma prior to all experiments. The cells lines were cultivated in DMEM supplemented with $10 \%$ fetal calf serum (FCS), $100 \mathrm{U} / \mathrm{ml}$ penicillin-streptomycin and $2 \mathrm{mM}$ L-glutamine.

Antibodies and proteins. Recombinant galectin-3 was obtained from Abcam or produced as previously described (17). Asialofetuin and fetuin were obtained from Sigma-Aldrich; Merck KGaA, collagen type R (a mixture of $90 \%$ collagen type I and $10 \%$ collagen type III) was from SERVA Electrophoresis $\mathrm{GmbH}$ and EHS laminin from Roche Diagnostics GmbH. The hybridoma cell line expressing a monoclonal antibody against galectin-3 (M3/38) (18) was obtained from the American Type Culture Collection (ATCC).

Cell extraction and affinity purification of galectin-3. A total of $10^{5}$ cells were seeded in 6-cm Petri dishes and cultivated to $>90 \%$ confluency. Monolayers were washed with ice-cold phosphate-buffered saline (PBS) and then solubilized for 10 min at $4^{\circ} \mathrm{C}$ with PBS, $5 \mathrm{mM}$ EDTA, $1 \%$ Triton X-100, containing protease inhibitors (extraction buffer). The cell extract was centrifuged for $10 \mathrm{~min}$ at $15,000 \mathrm{xg}$ at $4^{\circ} \mathrm{C}$. A total of $500 \mu$ l each of the supernatant (derived from 1,000,000 cells) were either mixed with $200 \mu 1$ lactose-agarose (Sigma-Aldrich; Merck KGaA) or agarose (Merck KGaA) and incubated at $4{ }^{\circ} \mathrm{C}$ for $90 \mathrm{~min}$ on a shaker. The gel slurry was washed 3 times with extraction buffer without Triton X-100. Bound proteins were eluted with $400 \mu 1$ of extraction buffer without Triton X-100 containing either $100 \mathrm{mM}$ lactose or $100 \mathrm{mM}$ sucrose. A Bradford assay with Bio-Rad Protein dye reagent was used for protein determination (Bio-Rad Laboratories, Inc.).

Western blot analysis. Western blot analyses were performed essentially as previously described (19). Briefly, proteins (for the preparation of cell solubilisates please see previous above) were separated by $10 \%$ SDS-PAGE and transferred onto nitrocellulose filters. Filters were then blocked for $1 \mathrm{~h}$ in Tris-buffered saline (TBS) containing 5\% milk powder and $0.1 \%$ Tween-20 (TBS-Tween). Filters were further incubated overnight at $4^{\circ} \mathrm{C}$ with the M3/38 antibody (sc-23938; Santa Cruz Biotechnology, Inc.) diluted 1:500 in TBS-Tween and then washed 3 times (10 min each) in TBS-Tween at room temperature. Incubation with HRP-conjugated secondary antibodies (goat anti-rat IgG coupled to horseradish peroxidase from Jackson ImmunoResearch, cat. no. 112-035-003), diluted 1:2,000 in TBS-Tween, was performed for $1 \mathrm{~h}$ at room temperature. Filters were then again washed in TBS-Tween and antibody binding was visualized using the Pierce ${ }^{\mathrm{TM}}$ ECL Plus Western Blotting Substrate (Thermo Fisher Scientific, Inc.) and the ChemiDoc XRS system (Bio-Rad Laboratories, Inc.).

Cell adhesion assay. The assay was carried out essentially as previously described (20). In brief, proteins were diluted to final concentrations in PBS, spotted ( $3 \mu 1$ per spot) onto plastic Petri dishes $(6 \mathrm{~cm}$ in diameter) and incubated for $2 \mathrm{~h}$ in a humid atmosphere at room temperature. Dishes were then washed once with PBS containing 5\% heat-inactivated bovine serum albumin (BSA) and incubated in the same solution for $1 \mathrm{~h}$ at room temperature. Dishes were subsequently washed 3 times with PBS. Cell suspensions $\left(1 \times 10^{6}\right.$ cells $/ \mathrm{ml}$ in serum-free DMEM, $3 \mathrm{ml}$ per dish) were then added and incubated at $37^{\circ} \mathrm{C}$ with the substrata for up to $4 \mathrm{~h}$. Subsequently, non-adherent cells were removed and the number of adherent cells monitored microscopically.

For the analysis of the carbohydrate dependency of cell adhesion to galectin-3, asialofetuin, fetuin ( $1 \mathrm{mg} / \mathrm{ml}$ each), lactose, or sucrose (50 $\mathrm{mM}$ each) were present in the medium throughout the assay.

Cell surface ELISA. Cells (10,000 cells per well) were seeded in 96-well plates and allowed to adhere in complete culture medium for $5 \mathrm{~h}$ and then incubated at room temperature in serum-free DMEM overnight. The medium was then changed to DMEM with or without $50 \mathrm{mM}$ lactose or sucrose and cells incubated for $1 \mathrm{~h}$ at $37^{\circ} \mathrm{C}$. Following a washing step with DMEM, cells were incubated with M3/38 antibody (sc-23938; Santa Cruz Biotechnology, Inc.) diluted 1:500 in DMEM $1 \%$ BSA for $1 \mathrm{~h}$ at room temperature. Following another washing step, the cells were fixed for $10 \mathrm{~min}$ at room temperature in $4 \%$ formaldehyde in PBS, washed with PBS and blocked for 30 min with 5\% BSA in PBS. The cells were then incubated with secondary anti-rat IgG antibody coupled to horseradish peroxidase (cat. no. 112-035-003; Jackson ImmunoResearch) diluted 1:2,000 for $1 \mathrm{~h}$ at room temperature and then washed with PBS. ABTS (from Roche Diagnostics $\mathrm{GmbH}$ ) in acetate buffer was used as enzyme substrate and 


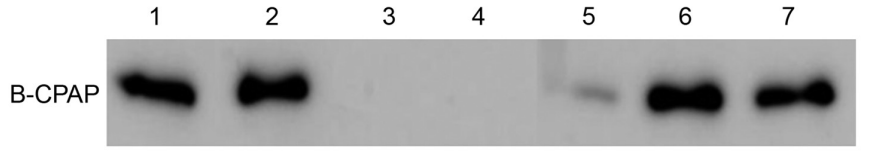

Cal-62
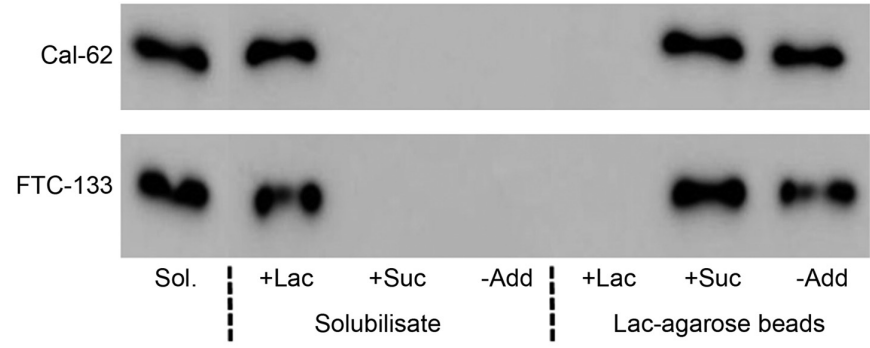

Figure 1. Galectin-3 expressed by thyroid carcinoma cells is functionally active. Western blot analysis of thyroid carcinoma cell-intrinsic galectin-3 Solubilisates (Sol.) of thyroid carcinoma cells B-CPAP, Cal-62 and FTC-133 (lane 1) following incubation with lactose-agarose beads either in the presence of $50 \mathrm{mM}$ lactose (lane 2), of $50 \mathrm{mM}$ sucrose (lane 3) or without additives (lane 4). Lanes 5 to 7 correspond to lanes 2 to 4 and show galectin-3 that could be eluted from lactose agarose beads upon boiling in SDS-PAGE sample buffer. Equal volumes were loaded for lanes 2 to 4 and lanes 5 to 7 , respectively. Galectin-3 specific M3/38 antibody was used for specific antigen detection. In lane 1 the solubilisate of approximately 50,000 cells was loaded.

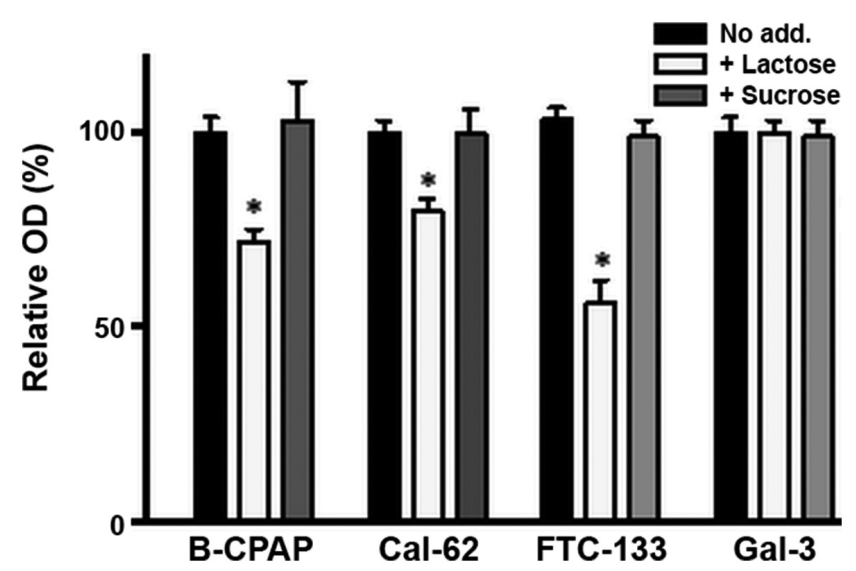

Figure 2. Interaction of galectin-3 expressed on the cell surface of thyroid carcinoma cells is partially carbohydrate-dependent and -independent. Thyroid carcinoma cells were cultivated in 96-well plates and cell surface-expressed galectin-3 was detected by ELISA in untreated cells or in cells pretreated with $1 \mathrm{mg} / \mathrm{ml}$ fetuin or asialofetuin or $50 \mathrm{mM}$ lactose or sucrose. Optical density of untreated cells was set as $100 \%$ after the optical density of background binding (incubation with secondary antibody only) has been subtracted. The results of one typical assay (performed in triplicates) out of three independent experiments are shown. In control experiments, galectin-3 (Gal-3) was coated at a concentration of $10 \mathrm{ng} / \mathrm{ml}$ and treated identical to thyroid carcinoma cells. Significant differences compared to the control are depicted with asterisks $\left({ }^{*} \mathrm{P}<0.05\right)$

optical density was measured at $405 \mathrm{~nm}$. In control experiments, cells were incubated with secondary antibodies only.

Video time lapse analysis. Cells were seeded into pre-coated (20 $\mu \mathrm{g} / \mathrm{ml}$ galectin-3 or EHS laminin) 24-well plates (2,000 cells per well) and allowed to adhere overnight. Video time lapse analyses were then carried out as previously described (21). Briefly, the culture plates were transferred to a pre-heated $\left(37^{\circ} \mathrm{C}\right)$, gassed $\left(5 \% \mathrm{CO}_{2} /\right.$ air $)$ and humidified chamber fitted onto an inverted microscope (Axiovert $200 \mathrm{M}$; Carl Zeiss AG) equipped with a motorized cross-stage. Images were recorded with Axiovision (Rel. 4.8) every $10 \mathrm{~min}$ for $24 \mathrm{~h}$ with the AxioCamMR3 (Carl Zeiss AG). Cell movements were tracked and analysed in Image J (version 1.49n) using the ImageJ plugin MTrackJ.

Statistical analysis. For statistical analysis, one-way-ANOVA with Tukey's multiple comparisons post hoc test were carried out using GraphPad Prism 6 Software (GraphPad Software Inc.). P-values $<0.05$ were considered to indicate statistically significant differences compared to the control experiments.

\section{Results}

Galectin-3 from thyroid carcinoma cells harbors a functionally active CRD. To analyze whether galectin-3 from thyroid carcinoma cells is functionally intact, cell solubilisates from B-CPAP, Cal-62 or FTC-133 cells were incubated with lactose-agarose beads in the absence or presence of $50 \mathrm{mM}$ lactose or sucrose. Bound material was then eluted with a lactose- or sucrose-containing buffer. Western blot analyses (Fig. 1) documented that galectin-3 present in cell solubilisates was lost upon incubation with lactose agarose in the absence of additives or in the presence of $50 \mathrm{mM}$ sucrose, but not in the presence of $50 \mathrm{mM}$ lactose. Vice versa, galectin-3 was present in the eluate (treatment with SDS sample buffer at $100^{\circ} \mathrm{C}$ ) of lactose agarose beads incubated without additives or in the presence of $50 \mathrm{mM}$ sucrose, but not in the presence of $50 \mathrm{mM}$ lactose. Comparable data were obtained for all 3 carcinoma cell lines, indicating that the CRD of intrinsic galecin-3 is functionally active in this type of tumor cells.

Cell surface-bound galectin-3 only partially interacts via its CRD with the plasma membrane. Thyroid carcinoma cells were seeded in 96-well plates and cultivated to confluency. For the cell surface ELISA, cells were incubated with DMEM medium with or without $50 \mathrm{mM}$ lactose or sucrose for $1 \mathrm{~h}$, followed by incubation with a galectin-3-specific antibody. In all cell lines, the amount of galectin-3 expressed on the cell surface was substantially reduced (approximately 25\% in B-CPAP or Cal-62 and approximately 50\% in FTC-133 cells), but not completely abolished by lactose treatment, whereas sucrose treatment did not exert any evident effects (Fig. 2). Treatment with galectin-3 immobilized on plastic with lactose or sucrose did not exert any evident effects (Fig. 2). These data indicate that only a fraction of extracellular galectin-3 interacts with the plasma membrane via the CRD. Notably, treatment with asialofetuin or fetuin led to more strongly reduced OD values in comparison to treatment with simple carbohydrates (data not shown). However, such a reduction also occurred for immobilized galectin-3, suggesting that asialofetuin or fetuin bound to galectin-3 interfere with binding of the primary antibody.

Galectin-3 promotes the adhesion of thyroid carcinoma cells via the CRD. Galectin-3 or collagen $\mathrm{R}$ were immobilized on the surface of Petri dishes in selected areas and single cell suspensions of thyroid carcinoma cells were incubated with the immobilized proteins either in the absence or in the presence of asialofetuin $(1 \mathrm{mg} / \mathrm{ml})$, fetuin $(1 \mathrm{mg} / \mathrm{ml})$, lactose $(50 \mathrm{mM})$ or sucrose $(50 \mathrm{mM})$ for $4 \mathrm{~h}$. Following the removal of unbound 

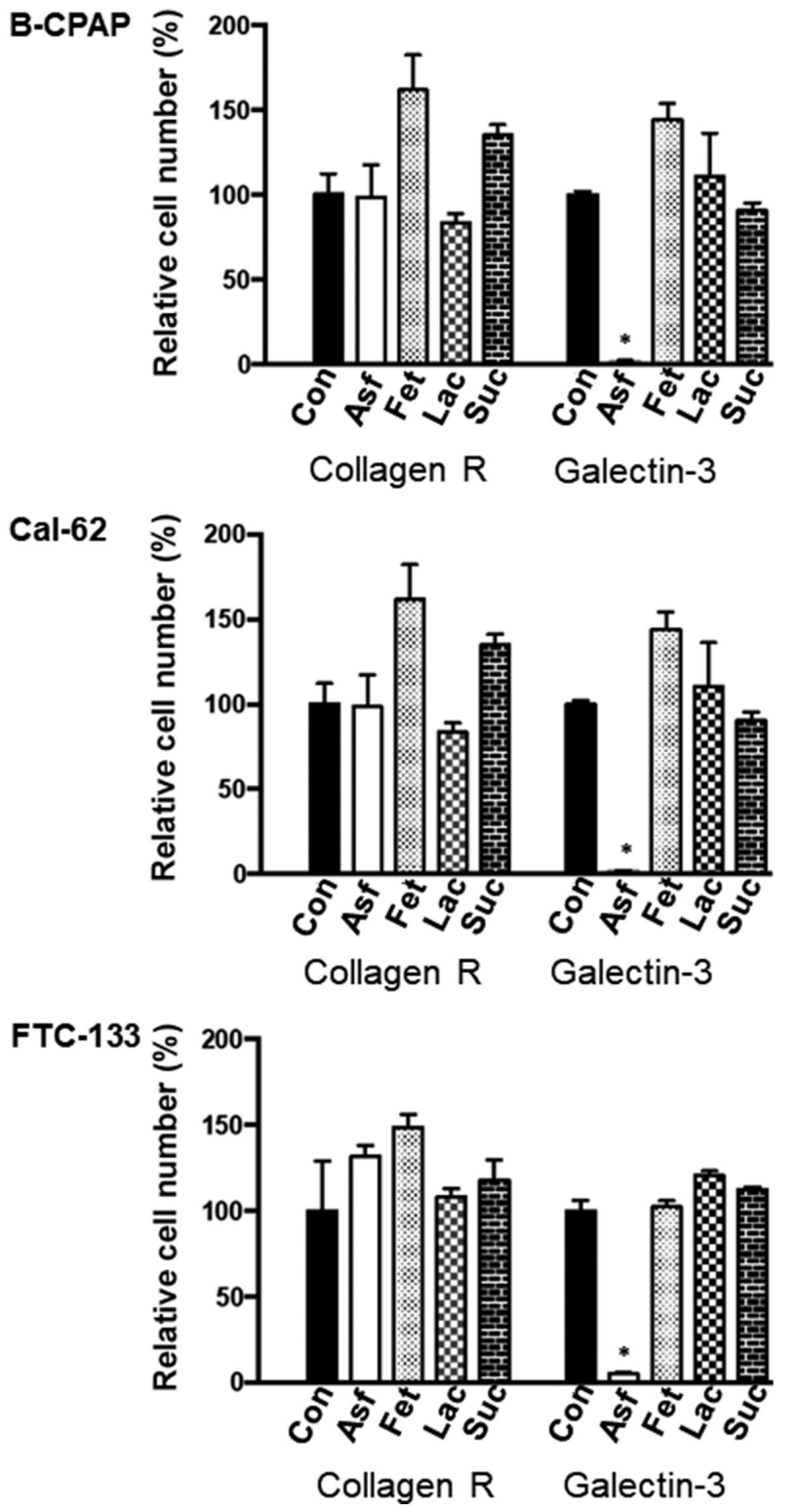

Figure 3. Thyroid carcinoma cells adhere to galectin-3 in a carbohydrate-dependent manner. Cells were allowed to adhere to a galectin-3 or a collagen R substrate for $4 \mathrm{~h}$ in the absence or presence of $1 \mathrm{mg} / \mathrm{ml}$ asialofetuin or fetuin, or $50 \mathrm{mM}$ lactose or sucrose. Number of adherent cells in randomly selected areas was determined microscopically. The number of adherent cells in the absence of additives was artificially set as $100 \%$ and the other values were adjusted accordingly. Summarized data from three independent experiments are shown. Significant differences compared to the control are shown with asterisks $(" \mathrm{P}<0.05)$.

cells, adherent cells were counted microscopically in randomly selected areas. All cell lines were able to adhere to galectin-3 or collagen R (Fig. 3). Asialofetiun inhibited the adhesion of carcinoma cells to galectin- 3 by almost $100 \%$, but not to collagen $\mathrm{R}$, whereas fetuin, lactose or sucrose were almost ineffective. This finding is in accordance with previous data by the authors demonstrating that cell adhesion to galectin occurs predominantly in a carbohydrate-dependent manner (20). It should be emphasized that asialofetuin is multivalent and carries terminal carbohydrate structures with a higher affinity to galectin-3 in comparison to fetuin or lactose (22). It is also noteworthy to mention that cells adherent to galectin-3 continued to proliferate in normal cell culture medium for at

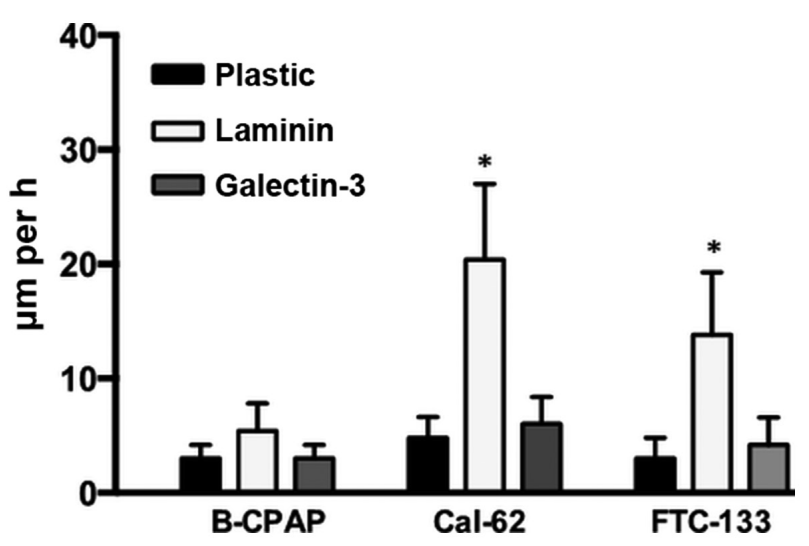

Figure 4. Substrate-offered galectin-3 does not promote cell migration. Single cell migration on cell culture plastic (pre-treated with heat-inactivated BSA), galectin-3 or laminin substrata as revealed by video time lapse assay. Analysis was performed for $24 \mathrm{~h}$ and the path length of 20 cells per well was analyzed. Histogram shows the mean velocity of cells in $\mu \mathrm{m}$ per $\mathrm{h}+\mathrm{SD}$. A total of 2 independent experiments were performed in duplicate (i.e., 2 wells) and 4 selected areas were investigated microscopically per well. Significant differences compared to the control are depicted with asterisks $\left({ }^{*} \mathrm{P}<0.05\right)$.

least further three days. Hereafter, a confluent cell monolayer has been developed. During this time-period no significant signs of cell death were observed.

Galectin-3 does not promote the migration of thyroid carcinoma cells. Thyroid carcinoma cells were seeded onto plastic, galectin-3 or laminin substrata and the migration paths of individual cells were recorded for $24 \mathrm{~h}$ as previously described (21). Cells were mobile on a laminin substrate to varying degrees: $5.4 \mu \mathrm{m} / \mathrm{h}$ for B-CPAP, $20.4 \mu \mathrm{m} / \mathrm{h}$ for Cal-62 and $13.8 \mu \mathrm{m} / \mathrm{h}$ for FTC-133 cells (Fig. 4). The velocity of cells on a galectin-3 substrate was considerably lower (3.0 to $6.0 \mu \mathrm{m} / \mathrm{h}$ ) and comparable to the one on untreated cell culture plastic, indicating that substrate-immobilized galectin-3 did not promote cell migration.

\section{Discussion}

The present study provides evidence that intrinsic galectin-3 of thyroid carcinoma cells harbors an active CRD that is partially responsible for the molecular interaction with the plasma membrane. When offered as a substrate, galectin-3 promotes adhesion but not migration of thyroid carcinoma cells.

As also demonstrated for other cellular sources, the functional activity of thyroid carcinoma-derived galectin-3 is not dependent on the presence of reducing agents as necessary for other types of galectins, such as galectin-1 $(23,24)$; i.e., the molecule could be efficiently affinity-purified with lactose-agarose under oxidizing conditions. In principle, 3 types of interactions of galectin-3 with its ligands are possible: Interactions via the CRD with i) specific carbohydrate structures; or ii) with molecules that mimic carbohydrate structures; or iii) interactions that are independent of the CRD. Type 'ii' or 'iii' interactions are likely for interactions of galectin-3 in the intracellular environment, for example with Bcl-2, Ras or synexin (22). In addition, homophilic interactions of galectin-3 can be type 'ii' or 'iii' interactions (15). Moreover, specific peptides can mimic carbohydrate structures and are recognized by galectin-3 via its CRD (25). 
However, as only a fraction of the molecule could be released from the plasma membrane with specific carbohydrates, carbohydrate-independent molecular interactions must also take place. The likelihood for the presence of such type of galectin-3 ligands has been documented for mast cells (26) and Sf9 insect cells (27). It has to be emphasized that the extent to which the CRD-dependent interactions of galectin-3 with the plasma membrane are realized via carbohydrates or carbohydrate-mimicking structures cannot be distinguished. Independently of their exact molecular nature, galectin-3 specific ligands are expressed on the plasma membrane of thyroid carcinoma cells in such an amount, that they allow stable cell adhesion. As this adhesion process can be almost completely inhibited by asialofetuin, the CRD of galectin-3 seems to be of predominant importance under this aspect. This is in accordance with previous data that suggest a more ubiquitous expression of such galectin-3 specific-ligands in a variety of different cells (20). However, as long as their precise molecular nature is not identified, the valuation of the functional relevance raised by these molecular interactions remains a difficult task.

Substrate-bound galectin-3 did not the promote migration in the type of assay used in the present study. However, intracellular galectin-3 has recently been shown to promote the migration of thyroid carcinoma cells, particularly under hypoxic conditions through multiple signaling pathways (28). In colon cancer cells, it has been demonstrated that soluble extracellular galectin-3 promotes cell migration in a wound healing assay (29). Thus, it would be of interest to reveal whether such effects are cell line-dependent or whether they vary dependent on how the lectin is offered, i.e., in solution or as immobilized substrate. It is noteworthy to mention that no evidence that soluble galectin-3 provokes the migration of carcinoma cells in Boyden chamber assays was found, even when used at a concentration of $5.0 \mu \mathrm{g} / \mathrm{ml}$ that had been shown to induce the migration of monocytes (30). Thyroid carcinoma cells are per se able to migrate in such types of assays, as revealed by their migration across laminin-coated porous membranes, when 5\% FCS was used as an attractant (unpublished data). By contrast, Zheng et al (28) demonstrated that intrinsic galectin-3 induced by hypoxia promoted the migration rate of thyroid carcinoma cells in Boyden chamber assays, when serum was used as an attractant. However, these studies did not allow the discrimination between extra- and intracellular expressed galectin-3.

At present, the relevance of galectin-3 in the context of thyroid cancer is mainly focused on cancer diagnosis and cancer imaging (15,31). However, a limited number of experimental studies have suggested a contribution of galectin-3 in the apoptosis $(11)$, proliferation $(10,11)$ and migration (28) of thyroid tumor cells. Unfortunately, these studies did not distinguish between extra- and intracellular galectin-3, or focused on the intracellular expression of galectin-3; i.e., galectin-3-Ras (11) or galectin-3-Bax interactions (10).

In conclusion, the present study provides evidence of the complex interactions of galectin-3 with a variety of extracellular ligands in thyroid carcinoma cells. The precise identification of such ligands, as well as conditions that allow an upregulation of extracellular galectin-3 or its ligands is an obvious challenge for the future. Such types of studies may increase the relevance of galectin-3 in the treatment of thyroid cancer, particularly in the context of antibody-based therapies.

\section{Acknowledgements}

Not applicable.

\section{Funding}

No funding was received.

\section{Availability of data and materials}

All data generated or analyzed during this study are included in this published article or are available from the corresponding author on reasonable request.

\section{Authors' contributions}

All authors (JW, AG, DK, SF, NV and RP) made substantial contributions to the design of the study or the acquisition, analysis, or interpretation of data for the study. All authors (JW, AG, DK, SF, NV and RP) were involved in drafting the work or revising it critically for important intellectual content. All authors approved the final version to be published and agree to be accountable for all aspects of the work in ensuring that questions related to the accuracy or integrity of any part of the work are appropriately investigated and resolved.

\section{Ethics approval and consent to participate}

Not applicable.

\section{Patient consent for publication}

Not applicable.

\section{Competing interests}

The authors declare that they have no competing interests.

\section{References}

1. Kitahara CM and Sosa JA: Understanding the ever-changing incidence of thyroid cancer. Nat Rev Endocrinol 16: 617-618, 2020.

2. Laha D, Nilubol $\mathrm{N}$ and Boufraqech M: New therapies for advanced thyroid cancer. Front Endocrinol (Lausanne) 11: 82, 2020.

3. D'Alessandria C, Braesch-Andersen S, Bejo K, Reder S, Blechert B, Schwaiger M and Bartolazzi A: Noninvasive In vivo imaging and biologic characterization of thyroid tumors by immunoPET targeting of galectin-3. Cancer Res 76: 3583-3592, 2016.

4. De Rose F, Braeuer M, Braesch-Andersen S, Otto AM, Steiger K, Reder S, Mall S, Nekolla S, Schwaiger M, Weber WA, et al: Galectin-3 targeting in thyroid orthotopic tumors opens new ways to characterize thyroid cancer. J Nucl Med 60: 770-776, 2019.

5. Cardoso AC, Andrade LN, Bustos SO and Chammas R: Galectin-3 Determines tumor cell adaptive strategies in stressed tumor microenvironments. Front Oncol 6: 127, 2016.

6. Gordon-Alonso M, Bruger AM and van der Bruggen P: Extracellular galectins as controllers of cytokines in hematological cancer. Blood 132: 484-491, 2018. 
7. Johannes L, Jacob R and Leffler H: Galectins at a glance. J Cell Sci 131: 131, 2018.

8. Gordon-Alonso M, Hirsch T, Wildmann C and van der Bruggen P: Galectin-3 captures interferon-gamma in the tumor matrix reducing chemokine gradient production and T-cell tumor infiltration. Nat Commun 8: 793, 2017.

9. Xue H, Liu L, Zhao Z, Zhang Z, Guan Y, Cheng H, Zhou Y and Tai G: The N-terminal tail coordinates with carbohydrate recognition domain to mediate galectin-3 induced apoptosis in T cells. Oncotarget 8: 49824-49838, 2017.

10. Harazono Y, Kho DH, Balan V, Nakajima K, Hogan V and Raz A: Extracellular galectin-3 programs multidrug resistance through $\mathrm{Na}^{+} / \mathrm{K}^{+}$-ATPase and P-glycoprotein signaling. Oncotarget 6 : 19592-19604, 2015.

11. Nangia-Makker P, Balan V and Raz A: Regulation of tumor progression by extracellular galectin-3. Cancer Microenviron 1: 43-51, 2008.

12. Gao X, Balan V, Tai G and Raz A: Galectin-3 induces cell migration via a calcium-sensitive MAPK/ERK1/2 pathway. Oncotarget 5: 2077-2084, 2014.

13. Elad-Sfadia G, Haklai R, Balan E and Kloog Y: Galectin-3 augments K-Ras activation and triggers a Ras signal that attenuates ERK but not phosphoinositide 3-kinase activity. J Biol Chem 279: 34922-34930, 2004

14. Levy R, Grafi-Cohen M, Kraiem Z and Kloog Y: Galectin-3 promotes chronic activation of K-Ras and differentiation block in malignant thyroid carcinomas. Mol Cancer Ther 9: 2208-2219, 2010.

15. Bartolazzi A, Sciacchitano S and D'Alessandria C: Galectin-3 The impact on the clinical management of patients with thyroid nodules and future perspectives. Int J Mol Sci 19: E445, 2018.

16. Lavra L, Rinaldo C, Ulivieri A, Luciani E, Fidanza P, Giacomelli L, Bellotti C, Ricci A, Trovato M, Soddu S, et al: The loss of the p53 activator HIPK2 is responsible for galectin-3 overexpression in well differentiated thyroid carcinomas. PLoS One 6: e20665, 2011.

17. Kuklinski S and Probstmeier R: Homophilic binding properties of galectin-3: Involvement of the carbohydrate recognition domain. J Neurochem 70: 814-823, 1998

18. Ho MK and Springer TA: Mac-2, a novel 32,000 Mr mouse macrophage subpopulation-specific antigen defined by monoclonal antibodies. J Immunol 128: 1221-1228, 1982.

19. Pesheva P, Urschel S, Frei K and Probstmeier R: Murine microglial cells express functionally active galectin-3 in vitro. J Neurosci Res 51: 49-57, 1998a.

20. Pesheva P, Kuklinski S, Schmitz B and Probstmeier R: Galectin-3 promotes neural cell adhesion and neurite growth. J Neurosci Res 54: 639-654, 1998b.
21. Lobastova L, Kraus D, Glassmann A, Khan D, Steinhäuser C, Wolff C, Veit N, Winter J and Probstmeier R: Collective cell migration of thyroid carcinoma cells: A beneficial ability to override unfavourable substrates. Cell Oncol (Dordr) 40: 63-76, 2017.

22. Knibbs RN, Agrwal N, Wang JL and Goldstein IJ: Carbohydratebinding protein 35. II. Analysis of the interaction of the recombinant polypeptide with saccharides. J Biol Chem 268: 14940-14947, 1993.

23. Fettis MM and Hudalla GA: Engineering reactive oxygen species-resistant galectin-1 dimers with enhanced lectin activity. Bioconjug Chem 29: 2489-2496, 2018.

24. Cedeno-Laurent F and Dimitroff CJ: Galectin-1 research in T cell immunity: Past, present and future. Clin Immunol 142: 107-116, 2012.

25. Anananuchatkul T, Chang IV, Miki T, Tsutsumi $\mathrm{H}$ and Mihara $\mathrm{H}$ : Construction of a stapled $\alpha$-helix peptide library displayed on phage for the screening of galectin-3-binding peptide ligands. ACS Omega 5: 5666-5674, 2020.

26. Frigeri LG and Liu FT: Surface expression of functional IgE binding protein, an endogenous lectin, on mast cells and macrophages. J Immunol 148: 861-867, 1992.

27. Inohara $\mathrm{H}$ and Raz $\mathrm{A}$ : Functional evidence that cell surface galectin-3 mediates homotypic cell adhesion. Cancer Res 55: 3267-3271, 1995.

28. Zheng J, Lu W, Wang C, Xing Y, Chen X and Ai Z: Galectin-3 induced by hypoxia promotes cell migration in thyroid cancer cells. Oncotarget 8: 101475-101488, 2017.

29. Wu KL, Kuo CM, Huang EY, Pan HM, Huang CC, Chen YF, Hsiao CC and Yang KD: Extracellular galectin-3 facilitates colon cancer cell migration and is related to the epidermal growth factor receptor. Am J Transl Res 10: 2402-2412, 2018.

30. Sano H, Hsu DK, Yu L, Apgar JR, Kuwabara I, Yamanaka T, Hirashima M and Liu FT: Human galectin-3 is a novel chemoattractant for monocytes and macrophages. J Immunol 165: 2156-2164, 2000.

31. Peplau E, De Rose F, Reder S, Mittelhäuser M, Scafetta G, Schwaiger M, Weber WA, Bartolazzi A, Skerra A and D'Alessandria C: Development of a chimeric antigen-binding fragment directed against human galectin-3 and validation as an immuno-positron emission tomography tracer for the sensitive in vivo imaging of thyroid cancer. Thyroid 30: 1314-1326, 2020.

This work is licensed under a Creative Commons Attribution-NonCommercial-NoDerivatives 4.0 International (CC BY-NC-ND 4.0) License. 